\title{
Will virtual mobility replace physical mobility?
}

\author{
K. Jauneikaite \& D. Misiunas \\ Vilnius Gediminas Technical University, Lithuania
}

\begin{abstract}
The structure of modal distribution in Vilnius still corresponds to principles of sustainable development, but the fact that changes in the Vilnius modal distribution are progressing very quickly is causing problems; the throughput of streets is unsatisfactory, traffic jams are never-ending, and non-motorized means of transport have lost their attractiveness because of poor safety and quality of the environment.

The main goal of surveys described in this paper are to estimate the influence of virtual mobility compared to the physical one and to use the data obtained for further planning of the urban transport system structure. To achieve this goal the following tasks were solved: the factors making the biggest influence on the type of trip have been identified, and the size and tendencies of virtual mobility at the target group point have been estimated.

The results of previous surveys suppose that virtual mobility will progressively be instrumental in decreasing the weight of physical trips. For proving this assumption, a representative part of the target group kept notes in their diaries of virtual mobility periodically, indicating how many physical trips they do daily and how many of them they can "avoid" by using the Internet or cell phones. The data obtained allowed us to estimate the changeable structure of the trip chain, decreasing the number of daily and duty journeys etc.

Keywords: virtual mobility, mobility diary, transport planning, land use planning, significance of travelling criteria.
\end{abstract}

\section{Introduction}

The market economy sees transport as the basis for speedy, convenient and safe realisation of transport-related economic relations between a producer and a user, also for the creation of conditions for the smooth movement of goods and passenger flows. The transport complex of Vilnius County consists of motor, 
railway and air transport that must not only compete but also supplement each other and work together in dealing with the common task: to achieve better satisfaction of the transportation need of the economy and population [1].

At present, motorization levels in Lithuania are increasing rapidly; it grew to 576 cars / per1000 inhabitants in the country and 647 cars / per1000 inhabitants in Vilnius in 2006. In 2004 public transport had carried 34,2\% of passengers, $35,1 \%$ of trips had been made on foot or by bicycle and $30,7 \%$ - by car. The structure of modal distribution in Vilnius still corresponds to the principles of sustainable development, but the fact that changes in the Vilnius modal distribution is progressing very quickly is causing problems; the throughput of streets is unsatisfactory, traffic jams are never-ending, and non-motorized means of transport have lost their attractiveness because of poor safety and quality of the environment.

The above mentioned problem is the most relevant to the capital city Vilnius, which is filled up every year with the flow of young people coming to work or to study. Vilnius city, if compared to the other administrative units, has the largest numbers of citizens using the Internet (already in $200557,6 \%$ of Vilnius citizens indicated that they have a personal computer at home, 30,4\% use the Internet every day or almost every day, $\sim 25 \%$ of the population of the smaller Lithuanian towns use the Internet every day [2]). Therefore, the target group, selected for our survey were the young people studying (working) and living in Vilnius, the age group $-20-24$ years.

\section{Model and object of the research}

Having analyzed the everyday trips of Vilnius citizens and the population of the other Lithuanian towns according to the type of trip, the goal of the trip, the number of trips and the reasons for choosing a particular vehicle [1,3] certain assumptions were made about the mobility of different groups of the population and the related problems. However, in the authors' opinion, the results of the current analysis cannot be the only factor having an influence on the strategic decisions when forming the population mobility management policy and planning a new infrastructure. Therefore, in order to create a future efficient methodology, including the monitoring of mobility factors, forecasting models, assessment of the most significant secondary factors, etc. the following main objects were formed:

1) to identify factors having the biggest influence on the type of trip;

2) to estimate the size and tendencies of virtual mobility at the target group point;

3) to evaluate the influence of changes in mobility to the changeable demand of physical movement and infrastructure necessary for it.

\subsection{Significance of factors that have an influence on population mobility}

Improvement (worsening of) individual parts (solutions) of the mobility management processes results in the changes in rationality of the remaining parts and the level of satisfaction of the concerned groups; thus, the first major step in 
the mobility management should be the objective significance of factors (hereinafter - indicators) that have an influence on population mobility. The objective significance of indicators was defined with the help of the entropy method [4]. We assume that $S=\left\{S_{1}, S_{2}, S_{3}, S_{4}, S_{5}\right\}$ is a discreet set of variants (trip on foot, by bicycle, public transport, car and Internet (see an explanation below)); $\mathrm{R}=\left\{\mathrm{R}_{1}, \mathrm{R}_{2}, \mathrm{R}_{3}, \mathrm{R}_{4}, \mathrm{R}_{5}\right\}$ is a set of indicators (duration, price, quality, environmental impact of the trip, safety of the chosen means); and $X=\left[\mathrm{X}_{\mathrm{ij}}\right]_{5 \times 5}$ is a solution matrix, were $x_{i j}$ is a value of indicator $S_{i}$ of variant $R_{j}$.

To have an objective assessment of the 5 variants with regard to all 5 indicators, the length of the trip equal for all discrete variants, $5 \mathrm{~km}$, and the goal of the trip (household trip; e-banking in case of the virtual mobility) were taken as a datum-level. Thus, the following matrix is obtained:

Table 1: Initial matrix for determination of significance.

\begin{tabular}{l|l|l|l|l|l}
\hline & Duration & Price & Quality & Influence A & Safety \\
\hline On foot & 45 & 0,1 & 8 & 10 & 4 \\
By bicycle & 25 & 0,2 & 8 & 10 & 4 \\
By PT & 13 & 1,1 & 5 & 6 & 6 \\
By car & 6 & 2 & 10 & 4 & 7 \\
By Internet & 1 & 0,1 & 10 & 10 & 10 \\
& min & $\min$ & $\max$ & $\max$ & $\max$ \\
\hline
\end{tabular}

Duration is measured in minutes, (see table 1), by estimating the average speed of the trip in the city. The price is given in litas calculating the average consumption of fuel; the trip on foot, by bicycle or by Internet should be rated symbolically. Quality and safety is a subjective assessment by the authors in points (the better quality the higher point); the environmental impact is also a subjective assessment by authors in points (the lower impact the higher point). As solving the task of significance some indicators should be minimised and the remaining ones should be maximised, the minimised values of the matrix should be taken in inverse values so that it could be assumed that all indicators will be maximised.

To have the same range of measurement, it is supposed that all significances of the initial matrix fluctuate from 0 to 1 . Thus, the initial matrix is normalised and with regard to each indicator the efficiency entropy level $\mathrm{E}_{\mathrm{j}}$ is determined, which allows assessing the change level $\mathrm{d}_{\mathrm{j}}$ of each indicator. As we assume that all indicators are equally important, then the objective significance of indicators is determined with the help of the following formula (1):

$$
\partial j \rightarrow \frac{d j}{\sum d j}
$$

To have a more prices estimation of the good and bad features of the trip variants being analysed it is necessary to estimate and calculate the influence of all changes on the final result of estimation. That is why the method of multicriteria complex proportional assessment of projects is applied [5]. The principle of the 
method is the following: a standardized matrix is concluded, the sums of minimizing and maximizing indicators that define $\mathrm{j}$ variant are calculated, which results in pluses $S_{+j}$ and minuses $S_{-j}$ of each variant. With the values of positive and negative features that define the variants, the relative significance of the variants being compared could be determined, which allows finding rationality of the concerned variants and priorities of choice (see table 2).

Table 2: $\quad$ Interim results of assessment of alternative ways of the trip.

\begin{tabular}{|c|c|c|c|c|c|c|c|}
\hline \multirow[b]{2}{*}{ Indicators } & \multirow{2}{*}{$\begin{array}{c}\text { Unit of } \\
\text { measure } \\
\text { of } \\
\text { indicators }\end{array}$} & \multirow{2}{*}{$\begin{array}{l}\text { Signifi- } \\
\text { cance } \\
\text { of } \\
\text { indica- } \\
\text { tors }\end{array}$} & \multicolumn{5}{|c|}{$\begin{array}{c}\text { Numeral values of standardized estimated } \\
\text { indicators }\end{array}$} \\
\hline & & & $\begin{array}{l}\text { On } \\
\text { foot }\end{array}$ & $\begin{array}{c}\text { By } \\
\text { bicycle }\end{array}$ & PT & $\begin{array}{l}\text { By } \\
\text { car }\end{array}$ & $\begin{array}{c}\text { By } \\
\text { Internet }\end{array}$ \\
\hline Duration & Min. & 0,61 & 0,312 & 0,159 & 0,09 & 0,042 & 0,007 \\
\hline Price & In litas & 0,284 & 0,001 & 0,002 & 0,009 & 0,016 & 0,001 \\
\hline Quality & Points & 0,019 & 0,004 & 0,004 & 0,002 & 0,005 & 0,005 \\
\hline $\begin{array}{l}\text { Influence } \\
\qquad \mathrm{A}\end{array}$ & Points & 0,041 & 0,01 & 0,01 & 0,006 & 0,004 & 0,01 \\
\hline Safety & Points & $\mathbf{0 , 0 4 7}$ & 0,006 & 0,006 & 0,009 & 0,011 & 0,015 \\
\hline \multicolumn{3}{|c|}{$\begin{array}{c}\text { Sum } \mathrm{S}_{+\mathrm{j}} \text { of maximising } \\
\text { standardised estimated } \\
\text { indicators }\end{array}$} & 0,02 & 0,161 & 0,099 & 0,058 & 0,008 \\
\hline \multicolumn{3}{|c|}{$\begin{array}{c}\text { Sum } \mathrm{S}_{-\mathrm{j}} \text { of minimising } \\
\text { standardised estimated } \\
\text { indicators }\end{array}$} & 0,313 & 0,02 & 0,017 & 0,02 & 0,03 \\
\hline \multicolumn{3}{|c|}{$\begin{array}{l}\text { Significance } Q_{\mathrm{j}} \text { of the way } \\
\text { of the trip }\end{array}$} & 0,085 & 0,263 & 0,22 & 0,16 & 0,084 \\
\hline
\end{tabular}

As shown in table 2, the duration of the trip is the most significant indicator when choosing the type of the trip (the objective significance: $61 \%$ of decision depends on the duration of the trip); the price of the trip is the second most significant indicator (28\%). Goodwin [6] noted that price impacts tend to increase over time as consumers have more options (related to increases in real incomes, automobile ownership, and now telecommunications that can substitute for physical travel). This supposes that virtual mobility, which allows the saving of time, and almost doesn't cost progressively, will be instrumental in the decrease of physical trips weight.

\subsection{Estimation of sizes and tendencies of virtual mobility}

Multimodalism is also important in the sense that someone can choose to successfully travel entirely by walking, bicycling, riding transit or avoiding travel altogether via the Internet and mobile phone [7]. Research by Liu et al. [8] demonstrates that intermodal transfers are time consuming and are avoided by 
travellers whenever possible; therefore, the success and functionality of multimodal options requires developing them as complete systems that connect intermodally.

That's why, in the below-given estimation of the objective significance and rationality of variants, the variant of virtual mobility (e.g., e-banking) is given as one of the alternatives of the trip. To find out the major trends of changes in population mobility and their impact on the city development, more attention should be paid to the types of population mobility, their changes depending on certain living conditions and possibilities (of population), e.g. how the physical mobility is influenced by the increasing significance of the virtual mobility (changes in the length and duration of trips, vehicles, etc.), etc. However, it is difficult to assess the above-mentioned issues by only operating physical numbers, as an information basis of local and virtual mobility does not exist. Residents of Vilnius make use of an alternative for mobility, i.e. communications and information networks. It could be presumed that due to the available opportunities some working places are established at home. Thus, it could be forecasted that the virtual mobility will rapidly expand and, if this prognosis comes true, it is probable that the physical mobility will decrease and this will result in lesser loads during rush hours. As this trend is seen as a reduced concentration of mobility, it will naturally solve the problem of transport system.

\subsubsection{Description of survey}

Development makes society get accustomed to new conditions and to change the way of thinking. More external efforts are not sufficient for that, as the internal resolution of inhabitants, predetermined by the level of knowledge, intellectual potential and involvement in competitive struggle is necessary. Education levels are higher in towns and surrounding regions, inhabitants of such towns and regions are apt to adopt modern IT technologies and stimulate implementation of new communication methods [9]. The created information networks in their turn have further impact not only on development of society; besides they have an impact on changes in land use priorities, decreased transport flows and so society isn't so sensitive to the lack of infrastructure.

On the initiative of the authors, with regard to all the mentioned research, it was decided to organise at least a 3-year long survey of the common target group (students). The previous surveys [1-3] showed that young and studying people are not only the most active IT technology users but also a less mobile group of the society with regard to transport trips. In 2006, more than 200 students of VGTU kept diaries of virtual mobility on different days of the week and indicated the goals of browsing the Internet, using mobile phones, etc. Respondents also indicated all physical trips that they had made by different transport means, also the duration and destination of those trips. Te general results of the survey were analysed with $95 \%$ probability and $1.9 \%$ error. An identical survey was repeated in 2007 and will be held in 2008 as well.

The results obtained were studied in 3 sections:

1) Identification of the main differences between the respondents, having the Internet at home and the respondents using the Internet in public access locations; 
2) Comparison of the specific features of the use of telecommunications and transport mobility by the respondents in 2006 and 2007;

3) Data processing according to the previously identified scheme of virtual mobility and transport trips by determining which physical trips could be replaced by the use of Internet.

\section{Results of virtual and physical mobility surveys}

\subsection{Main differences between the respondents having the Internet access at home and those having no Internet}

- Woman are more frequently provided with the Internet connection at home than men (75 and $77 \%$, respectively);

- The largest part of "Internauts" live at their parents home or in dormitories where the Internet access makes no additional costs, whereas the largest part of respondents having no Internet live in a rented dwelling where they would have to pay for the Internet connection;

- The respondents who have no Internet are more mobile than those who have it. Almost $5 \%$ of respondents having Internet at home made not a single daily trip, if compared to $1 \%$ of respondents having no Internet;

- The largest part of trips made by the "Internauts" are by passenger car (as drivers or passengers), while more than half of those having no Internet use public transport;

- The purpose of using the Internet is also different: most of their time the "Internauts" spend for entertainment, whereas those who have no Internet - use it for the search of information, electronic correspondence, etc.

\subsection{Main differences between the respondents in 2006 and 2007}

In $2006,75 \%$ of respondents had Internet access at home. In 2007 this proportion has increased by up to $87 \%$ of respondents. In 2006 one respondent spent on average $100 \mathrm{~min}$ on the Internet (of which most time was spent in the chat-rooms $-29 \mathrm{~min}$, for the search of information for work or studies $-23 \mathrm{~min}$., for the search of movies, music (downloading) - $17 \mathrm{~min}$. In 2007 the average time spent on the Internet has grown to $130 \mathrm{~min}$., see fig. 1, table 3. Evidently, the time duration spent on the Internet every day has been growing, especially between the respondents having no direct access to the Internet. In 2007 this duration was on average $26 \%$ larger than in 2006 .

When comparing the respondents by their purpose for the use of the Internet 2 trends could be singled out:

- $\quad$ between both target sub-groups time spent for direct work, info search and ordering goods or services over the Internet is not large and by its duration is similar between both those having the Internet access at home and those not;

in 2007, taking into account the increasing time spent on the Internet, the main differences become clear between those having the Internet at home and those not. Respondents having the Internet 
at home spend more time for entertainment, whereas those who have no Internet spend more time for the search of information for their studies or work, and this shows the growing trend for the young people to make one transport trip to the Internet access instead of one (several) trips to achieve the necessary goals without the use of Internet.

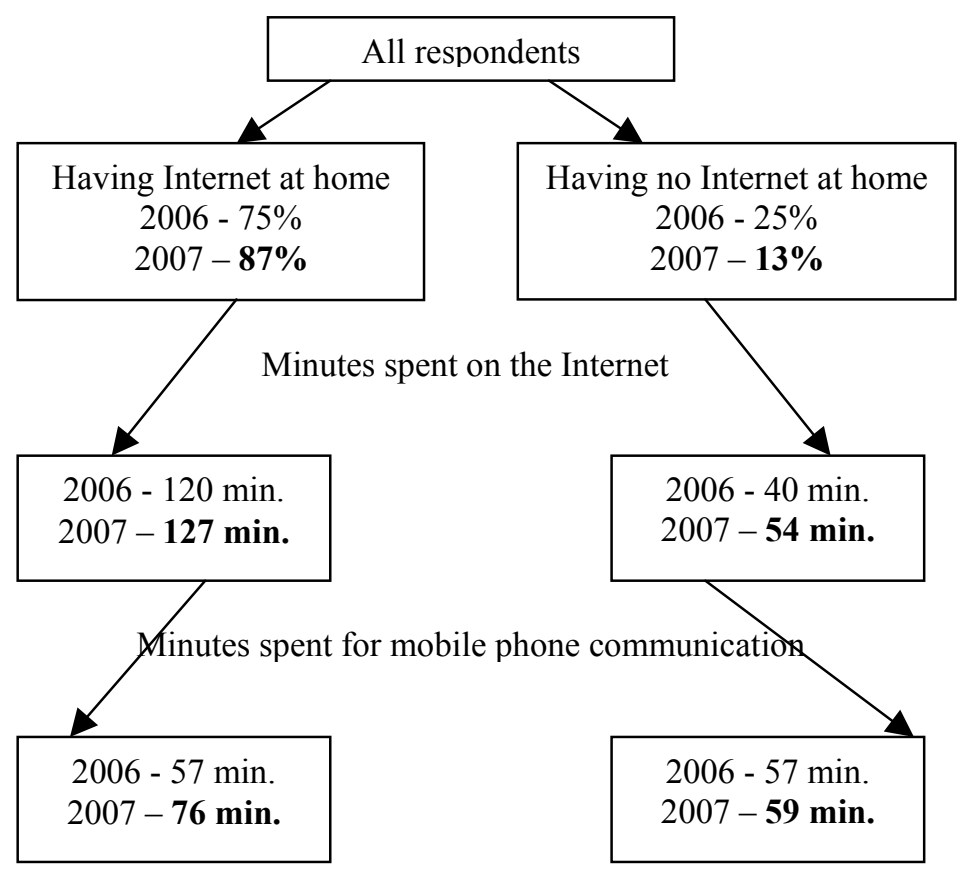

Figure 1: Duration of using Internet and a mobile phone (2006-2007).

Table 3: Time spent on the Internet according to the purpose of its use.

\begin{tabular}{|c|c|c|c|c|c|c|c|}
\hline \multicolumn{10}{|c|}{2006} \\
\hline \multicolumn{7}{|c|}{ Having Internet at home } & \multicolumn{3}{c|}{ Having no Internet at home } \\
\hline $\begin{array}{c}\text { Info } \\
\text { search }\end{array}$ & $\begin{array}{c}\text { Goods, } \\
\text { services }\end{array}$ & $\begin{array}{c}\text { Comm- } \\
\text { unication }\end{array}$ & $\begin{array}{c}\text { Entertain- } \\
\text { ment }\end{array}$ & $\begin{array}{c}\text { Info } \\
\text { search }\end{array}$ & $\begin{array}{c}\text { Goods, } \\
\text { services }\end{array}$ & $\begin{array}{c}\text { Comm- } \\
\text { unication }\end{array}$ & $\begin{array}{c}\text { Info } \\
\text { search }\end{array}$ \\
\hline $\begin{array}{c}24 \\
\text { min. }\end{array}$ & $\begin{array}{c}2 \\
\text { min. }\end{array}$ & $\begin{array}{c}53 \\
\text { min. }\end{array}$ & $\begin{array}{c}41 \\
\text { min. }\end{array}$ & $\begin{array}{c}19 \\
\text { min. }\end{array}$ & $\begin{array}{c}1 \\
\text { min. }\end{array}$ & $\begin{array}{c}14 \\
\text { min. }\end{array}$ & $\begin{array}{c}6 \\
\text { min. }\end{array}$ \\
\hline \multicolumn{70}{|c|}{$\mathbf{2 0 0 7}$} \\
\hline $\begin{array}{c}\text { Info } \\
\text { search }\end{array}$ & $\begin{array}{c}\text { Goods, } \\
\text { services }\end{array}$ & $\begin{array}{c}\text { Comm- } \\
\text { unication }\end{array}$ & $\begin{array}{c}\text { Info } \\
\text { search }\end{array}$ & $\begin{array}{c}\text { Info } \\
\text { search }\end{array}$ & $\begin{array}{c}\text { Goods, } \\
\text { services }\end{array}$ & $\begin{array}{c}\text { Commu- } \\
\text { nication }\end{array}$ & $\begin{array}{c}\text { Info } \\
\text { search }\end{array}$ \\
\hline $\begin{array}{c}18 \\
\text { min. }\end{array}$ & $\begin{array}{c}1 \\
\text { min. }\end{array}$ & $\begin{array}{c}53 \\
\text { min. }\end{array}$ & $\begin{array}{c}55 \\
\text { min. }\end{array}$ & $\begin{array}{c}39 \\
\text { min. }\end{array}$ & $\begin{array}{c}0 \\
\text { min. }\end{array}$ & $\begin{array}{c}12 \\
\text { min. }\end{array}$ & $\begin{array}{c}3 \\
\text { min. }\end{array}$ \\
\hline
\end{tabular}


In 2006 one respondent spent an average $57 \mathrm{~min}$. per day using mobile phone communication. In 2007 this number has increased up to $70 \mathrm{~min}$. per day. A more large increase in the duration of telephone calls and sending SMS was observed between those having the Internet access - in 2007 this proportion has increased by $25 \%$.

Almost 4\% of respondents made not a single daily trip, while in 2006 one respondent spent $91 \mathrm{~min}$. for physical trips. In 2007 this number came to $97 \mathrm{~min}$. (duration of one trip has grown but not the number of trips).

\subsection{Changeability of transport trips with the Internet}

The main assumption of the survey - the use of Internet replaces a certain number of transport trips. To check this assumption the earlier mentioned results of virtual and physical mobility diaries were used. To ensure a higher reliability of the survey the target group has been analyzed as a whole, without dividing it into sub-groups. The trips or time spent on the Internet, indicated by the respondents according to their goal, were divided into 4 groups:

a) Info search on the Internet (the equivalent - work-related transport trips);

b) Goods, services (the equivalent - household trips);

c) Communication (the equivalent - meeting the friends, relatives);

d) Entertainment (the equivalent - sport, movies, etc.).

Trying to make the survey more objective, initial data was assessed not in the quantitative but in percentage terms. Duration indicated by the respondents as spent on the Internet was re-calculated into times and attributed to the group according to the goal of use, thus, the obtained results could be compared to physical trips. Physical mobility is presented as a percentage of trips attributed to a certain travelling group (according to the goal) from the total number of the trips. The summarized results are given in table 4 .

Table 4: $\quad$ Percentage distribution of Internet use and transport trips according to the goal.

\begin{tabular}{|c|c|c|c|c|}
\hline $\begin{array}{c}\text { Type of } \\
\text { mobility }\end{array}$ & \multicolumn{4}{|c|}{ Goal } \\
\hline $\begin{array}{c}\text { Virtual } \\
\text { mobility }\end{array}$ & $\begin{array}{c}\text { Info search } \\
\text { for the } \\
\text { studies }\end{array}$ & $\begin{array}{c}\text { Goods, } \\
\text { services }\end{array}$ & Communication & Entertainment \\
\cline { 2 - 5 } & $26 \%$ & $5 \%$ & $\mathbf{4 7 \%}$ & $\mathbf{2 2 \%}$ \\
\hline \multirow{2}{*}{$\begin{array}{c}\text { Physical } \\
\text { mobility }\end{array}$} & Studies, work & $\begin{array}{c}\text { Goods, } \\
\text { services }\end{array}$ & Communication & Entertainment \\
\cline { 2 - 5 } & $54 \%$ & $26 \%$ & $\mathbf{7 \%}$ & $\mathbf{1 3 \%}$ \\
\hline
\end{tabular}

The results of this survey are, since data of at least several-year dynamics is not available so far, all by themselves not very representative, though the tendency is already clear - time spent on the Internet is getting longer, whereas the trips made for communication and entertainment is amounting to hardly $20 \%$ of all the trips 
made by the target group. The largest attention should be paid to the fact that the target group are 20-24 years old students, having relatively less business-related or social responsibilities than other social groups, thus, they have more time for an active communication "tête-à-tête".

Unfortunately, based on the results of this survey, those are people who spend nearly 3 hours per day for communication and entertainment (by watching movies, playing video games, etc), while their real trips, e.g. to the cinema or to the theatre, make less than $1 \%$ of all daily transport trips and this once again confirms the assumption made at the beginning of the survey about the changeability of trips with the Internet services.

\section{Conclusions and recommendations}

- To find out the major trends of changes in population mobility, their impact on the city development and to properly choose the mobility management measures, more attention should be paid to the types of population mobility, their changes depending on certain living conditions and possibilities of population, e.g. how the physical mobility is influenced by the increasing significance of the virtual mobility (changes in the length and duration of trips, vehicles, etc.). Planning organizations should encourage opportunities for advancement in telecommunications and other technologies and their impacts on travel behaviour to identify other means for meeting some of the transportation needs of the County residents and businesses [7].

- Duration of the trip is the most significant indicator when choosing the type of trip (the objective significance - $61 \%$ of decision depends on the duration of the trip); the price of the trip is the second most significant indicator (28\%). This supposes that virtual mobility, which allows savings in time and with little cost, will progressively be instrumental in decreasing the physical trips of importance.

- The number of young people having the Internet at home has been growing, time spent on the Internet has been rapidly increasing between both those having the Internet at home and those not. Differences between the goals of using the Internet become clear between those who have a free Internet access and those who have to make an additional trip to reach it.

- In the period 2006-2007 the number of people having the internet at home has increased from $75 \%$ to $87 \%$. It could be forecasted, that in the nearest future almost everybody from this target group will have the Internet at home and this allows us to assume that the model of physical mobility of young people will be even more changed. Already now the number of physical trips with the purpose to communicate, acquire knowledge or see a movie is very low, thus, it could happen that in two years the physical trips will only have a business-related goal and all the secondary trips related to goods, services and entertainment will be made via Internet. Therefore, the objective of the upcoming surveys is to study the goal for the use of Internet in the future. Will, at present, the most progressive society group (students), who will later become the most receptive user in both business and social society, use the Internet only for business and 
entertainment, thus, reducing the number of duty journeys and household (entertainment) daily trips, or create the working places at home and make only leisure-related transport trips?

- Results of mobility surveys can be one of the factors having the influence on the strategic decisions when forming the population mobility management policy and planning a new infrastructure.

- Yet, Lithuania has no information base of virtual mobility (especially of the physical change with the virtual). Therefore, in the authors' opinion, it would be necessary to organize constant observations, to carry out in a database monitoring of mobility indicators, to record the most significant secondary indicators which have influence on population mobility. Having created such a database and having determined the key relationships and the trends between the indicators, it will be possible to relate them to the need for population physical mobility and communication and to forecast means for meeting this need.

- The benefit of this work should be directly related to the selection of the strict mobility management means for the territory concerned (development of transport and communication network, traffic restriction and organization, purposeful reservation of the territory).

\section{References}

[1] Burinskienė M., Jauneikaite K. Development of Accessibility and Attractiveness of Vilnius. "ECOMM 2006" publications. Groningen, 2006.

[2] JSC „RAIT“ Vilnius inhabitants questionare results, 2005, 205 p.

[3] Burinskiene M., Jauneikaite K. Case Study of Mobility Management in Lithuania. Proc. of the $6^{\text {th }}$ Int. Conf. On Environmental Engineering. Vilnius, Volume II. pp.525-531, 2005.

[4] Ustinovičius L., Zavadskas E.K. Systemotechnical Evaluation of Effectiveness of Construction Investment. Technika, pp. 220. 2004.

[5] Ustinovičius L., Podvezko V. A. Mathematical Modellig Method of Determing Investment Efficiency in Construction. Modelling and Simulation of Business Systems. Proc. of the Int. Conf. Kaunas, pp. 160164, 2003.

[6] Litman T. Transportation Elasticities. How Prices and Other Factors Affect Travel Behavior. Victoria Transport Policy Institute, 2005.

[7] Incorporating TDM (transport demand management) into the Land Development Process. National Center for Transit Research. Center for Urban Transportation Research, University of South Florida, 2005.

[8] Liu R., Polzin S., Pendyala R. Simulation of the Effects of Intermodal Transfer Penalties on Transit Use. Transportation Research Record 1623, Transportation Research Board, National Research Council, Washington, D.C., pp. 88-95. 1998.

[9] Burinskiene M., Rudzkiene V. Presentation Strategy of Data Analysis and Knowledge for Web - Based Decision Support in Sustainable Urban Development. Proc. of the $3^{\text {rd }}$ Int. Conf. On Electronic Government. Zaragosa, pp. 150-155, 2004. 